\title{
Damage accumulation near the cold-expanded hole due to high- cycle fatigue by crack compliance method
}

\author{
Yu. G. Matvienko \\ Mechanical Engineering Research Institute of the Russian Academy of Science (IMASH RAN). 4 M. Kharitonievsky Per., \\ 101990 Moscow, Russia \\ matvienko7@yahoo.com, bttps://orcid.org/0000-0003-2367-0966
}

\author{
S. I. Eleonsky, V.S. Pisarev, M.D. Zajtsev \\ Central Aero-Hydrodynamics Institute named after Prof. N.E. Zhukovsky (Ts AGI). 1 Zhukousky Street, Zhukousky 140180 \\ Moscow Region, Russia. \\ juzzepka@mail.ru,bttps:/ /orcid.org/0000-0003-4345-067X \\ VSP5335@mail.ru, bttps://orcid.org/0000-0002-5378-609X \\ raytcev@list.ru
}

\begin{abstract}
The novel destructive method is implemented for quantitative assessment of fatigue damage accumulation in the stress concentration zone accompanied by residual stress due to cold expansion of the through-thickness hole. Damage accumulation is reached by preliminary cyclic loading of plane specimens with cold-expanded holes. Narrow notches, emanating from the hole edge at different stages of high-cycle fatigue, serve to manifest a damage level. These notches are inserted without applying external load. Deformation response to local material removing, caused by pure residual stress influence, is measured by electronic speckle pattern interferometry (ESPI) in terms of in-plane displacement components. Normalized values of the notch mouth open displacement (NMOD), in-plane displacement component at the initial point of the notch acting in the notch direction $\left(U_{0}\right)$, in-plane displacement component at the final point of the notch acting in the notch direction $\left(U_{1}\right)$ and the stress intensity factor (SIF) are used as current damage indicators. Numerical integration of curves, describing an evolution of each fracture mechanics parameter over lifetime, produces the damage accumulation function in an explicit form. It is established that all four fracture mechanics parameters give very close results.
\end{abstract}

KEYwORDS. Damage accumulation; Cold-expanded hole; High-cycle fatigue; Crack compliance method; Fracture mechanics parameters.

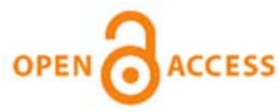

Citation: Matvienko, Yu. G., Eleonsky, S. I., Pisarev, V. S., Zaitsev, M. D., Damage accumulation near the cold-expanded hole due to high-cycle fatigue by crack compliance method, Frattura ed Integrità Strutturale, 59 (2022) 115-128.

Received: 19.10 .2021

Accepted: 20.10 .2021

Published: 01.01.2022

Copyright: (C) 2022 This is an open access article under the terms of the CC-BY 4.0, which permits unrestricted use, distribution, and reproduction in any medium, provided the original author and source are credited. 


\section{INTRODUCTION}

A

process of cold hole expansion widely serves to enhance the fatigue life of aerospace structures [1]. This process introduces a zone of compressive residual stresses around the hole, which, firstly, attenuates the crack appearance that leads to an increase the damage tolerance. Secondly, residual stresses reduce the effective stress intensity factor (SIF) range, thus decreasing fatigue crack growth rates [2]. Circumferential compressive residual stresses are especially beneficial for resisting fatigue when the plate with fastener holes undergoes a tensile load. The skin of lower wing surface is the most characteristic example of tensile-dominate airplane structure.

Information related to fatigue damage accumulation near cold-expanded holes is of considerable importance for reliable lifetime estimation. Wide set of both experimental and numerical researches are devoted to a characterization of the level of initial residual stresses and residual stresses evolution under various fatigue conditions [3-12]. In particular, the review [8] includes 81 references. Only a few of publications concern quantitative damage accumulation near cold-expanded holes due to fatigue loading. Available approaches are based on circumstantial damage indicators, which cannot be reliably established proceeding from direct physical measurements [13-15]. Implementation of the novel destructive method for quantitative assessment of fatigue damage accumulation in the stress concentration zone accompanied by the influence of residual stresses is the first subject of the present paper.

The key point of the involved approach resides in the fact that normalized values of singular and non-singular fracture mechanics parameters relevant to the narrow notch, which emanates from the plain hole in plane specimen at different stages of low-cycle fatigue, are used as damage indicators [16]. Investigated set of objects with different damage accumulation level consists of rectangular plates with stress concentrators (through-thickness circular holes), which have been tested under push-pull loading with different prefixed number of cycles. Deriving measurable fracture mechanics parameters, which are essential for quantitative description of damage accumulation process, is achieved by inserting a sequence of narrow notches under constant external load after preliminary low-cycle fatigue. These notches manifest a level of fatigue damage accumulation which is similar to the probe hole for residual stress energy release in the holedrilling method. The experimental approach employs optical interferometric measurements of the local deformation response to small notch length increments. Initial experimental data is represented by in-plane displacement components measured by ESPI along the notch surface. The transition from measured in-plane displacement components to required SIF and T-stress values follows from the relationships of modified version of the crack compliance method [17].

It seems quite natural to expand the above described methodology for quantifying damage accumulation in the vicinity of a cold-expanded hole. Remarkable capabilities of combining the crack compliance method and measurements of deformation response by ESPI to describe low-cycle fatigue influence on the evolution of fracture mechanics parameters, which are inherent in narrow notches inserted near cold-expanded holes, have been previously demonstrated [18-19]. The main difference between plain and cold-expanded hole resides in a presence of the residual stress field in the second case. Cold expansion induces a zone of residual compressive stresses around and through a hole, typically extending at least one radius around hole in the radial direction. That is why a validity of implementation of linear fracture mechanics relationships for transition from experimentally measured displacement components to required SIF values for notches emanating from the cold-expanded hole must be established. This procedure has been substantiated in Ref. [19] by revealing linear character of dependencies of NMOD and SIF values, obtained in the residual stress field, from externally applied stresses. This fact opens a way to implement the linear superposition principle for evaluation of residual SIF values.

Modified version of the crack compliance method has been implemented for quantifying an evolution of fracture mechanics parameters relevant to narrow artificial notch, which is emanated from the cold-expanded hole [18-19]. The objects of investigations were plane rectangular specimens of dimensions $180 \times 30 \times 5 \mathrm{~mm}$ with centre cold-expanded holes of diameter $2 r_{0}=4.0 \mathrm{~mm}$. The interference value was equal to $5 \%$. Therefore, high degree of cold expansion leads to circumferential residual stress of order $300 \mathrm{MPa}$ at the vicinity of the hole $[3,20]$. This means that direct penetration of the narrow notch to quantify the level of residual stress is quite difficult due to very high fringe density along notch surfaces. To overcome this problem, specimens were subjected to constant tensile loading before inserting a notch [1819]. This approach has the following disadvantages. First, deriving SIF values, related to the effect of pure residual stress, needs using the principal of superposition. Second, measurements of deformation response to local material removing can be performed only on one from two external faces of the specimen. Chosen surface was mandrel entrance side.

But, a significant difference in the magnitude of compressive residual stress has been established between the mandrel entry side and exit side. These data follow from both experimental and numerical analysis [2-12]. The stress value has a lower value at the entry face compared to the exit face. The residual tangential stress value varies gradually due to the 
material flow in axial direction caused by the mandrel reaching maximum value at exit side. Thus, simultaneous evaluation of fracture mechanics parameters on two opposite sides of the specimen is of considerable interest with respect to quantifying damage accumulation.

That is why deriving information, which concerns an evolution of fracture mechanics parameters, related to the narrow artificial notch emanating from cold-expanded hole in plane rectangular specimens under high-cycle fatigue on a basis of two-side measurements, is the second goal of this paper.

\section{SPECIMENS AND EXPERIMENTAL TECHNIQUE}

A luminium alloy $1163 \mathrm{~T}$ plane specimens of dimensions $200 \times 70 \times 10 \mathrm{~mm}$ with a centred through-thickness hole of nominal diameter $2 r_{0}=10.0 \mathrm{~mm}$ are used in the present research (Fig. 1a). Russian aluminium alloy1163T is analogous to AA2024 alloy. Mechanical properties of this alloy are the following: Young's modulus $E=74,000$ $\mathrm{MPa}$, yield stress $\sigma_{\mathrm{y}}=320 \mathrm{MPa}$ and Poisson's ratio $\mu=0.33$.

All coupons were cut from a single $1200 \times 800 \times 15 \mathrm{~mm}$ plate by the same milling technology so that their longitudinal axes were aligned with the plate rolling direction. Full set of specimens includes 7 units. Pilot holes of $9.82 \mathrm{~mm}$ in diameter were drilled, followed by a $10.0 \mathrm{~mm}$ final reaming. The degree of cold expansion is $0.5 \%$. Details of cold expansion technology are presented in Ref. [12]. Absence of residual stresses in all specimens has been established by data of probe hole drilling and further optical interferometric measurements of deformation response to local material removing [21]. Narrow artificial notches, emanating from the hole at different stages of high-cycle fatigue, serve to manifest a damage level. These notches are inserted without applying external load.

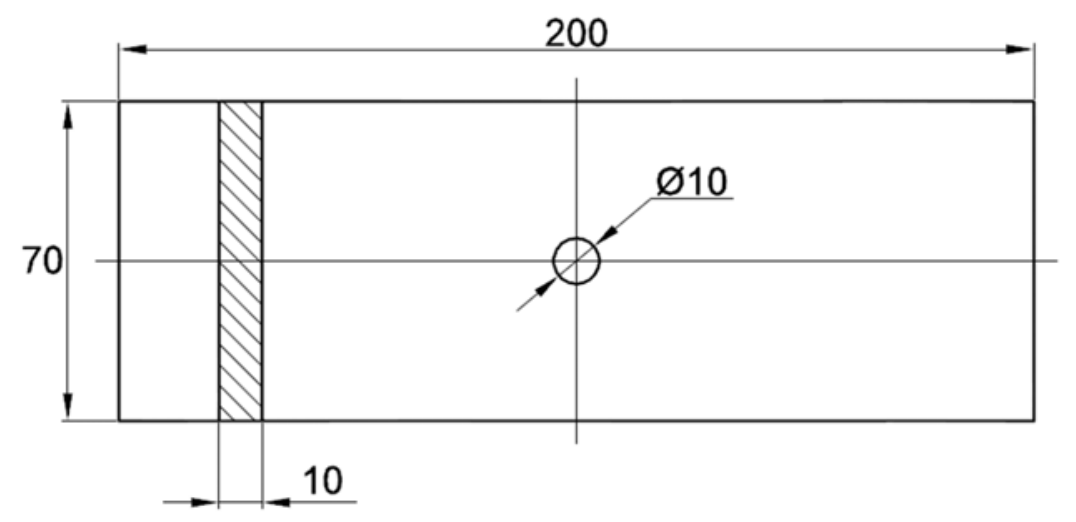

a

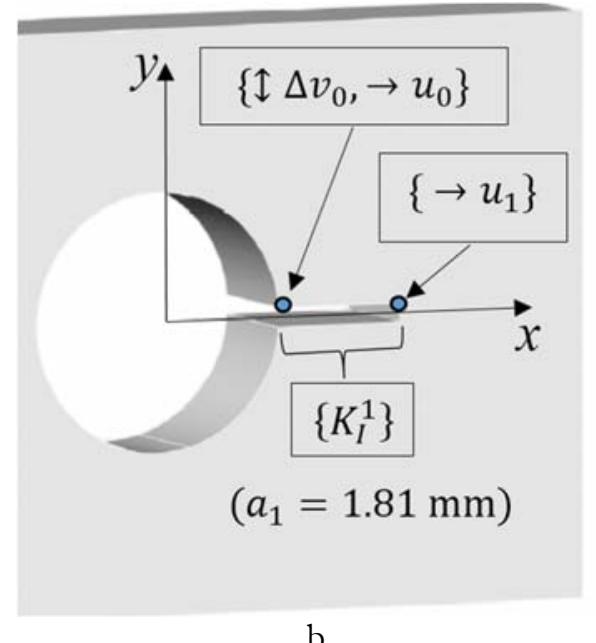

$\mathrm{b}$

Figure 1: Scheme of RSH specimens (a) and location of measurement points (b).

\begin{tabular}{lcccccc}
\hline Specimen & RSH_3 & RSH_4 & RSH_5 & RSH_6 & RSH_7 & RSH_1 \\
Number of cycles, $N$ & 0 & 20000 & 40000 & 60000 & 80000 & 110000 \\
Lifetime, \% & 0 & 18.2 & 36.4 & 54.6 & 72.7 & 100 \\
\hline
\end{tabular}

Table 1: Nomenclature of T5-H1 specimens and fatigue loading program.

The first specimen RSH_1 is used for lifetime estimation. The second specimen RSH_2 serves for a proper choice of the first and the second notch length proceeding from fringe resolution limit. The third specimen RSH_3 gives the characterization of residual stress before fatigue loading. Other specimens are subjected to uniaxial tension with stress range $\Delta \sigma=162 \mathrm{MPa}$ and stress ratio $\mathrm{R}=0.01$. The fatigue tests were carried out with a load frequency of $3 \mathrm{~Hz}$ in MTS250 servo hydraulic testing machine. Fracture of the reference specimen occurs after number of cycles $N_{F}=110000$. Number of cycles for each investigated specimen is listed in Tab. 1. Ref. [12] includes a comprehensive description of two-side simultaneous measurements of in-plane displacement components relevant to the artificial notch by electronic 
speckle-pattern interferometry (ESPI). A scheme of location of the measurement points and definition of corresponding fracture mechanics parameters are shown in Fig. 1b.

Relatively low interference level allows obtaining fracture mechanics parameters as a result of direct measurements of notch opening displacements without applying external tensile stress. Initial experimental information in terms of the notch opening displacements follows from a measurement of deformation response by ESPI to inserting the narrow notch. The original point of each non-symmetrical notch is located at the intersection of the hole boundary and the transverse symmetry axis of the specimen. SIF values are derived by using the relationships of modified version of the crack compliance method [17].

\section{EXPERIMENTAL DATA}

I nitial experimental information has a form of interference fringe patterns caused by local material removing without applying external load. Interferograms, obtained for the first notch in Specimen RSH_3 and Specimen RSH_7 in terms of the displacement component $v$, are presented in Ref. [12]. Interference fringe patterns relevant to opposite sides of Specimen RSH_6 are shown in Fig. 2. Analogous images are obtained for Specimens RSH_4 and RSH_5. Methodology of $v$-displacement component measurements on opposite crack borders and further determination of values of NMOD and crack opening displacement to the notch middle point (COD) is carefully described in Ref. [12]. These two parameters are essential for deriving SIF values.

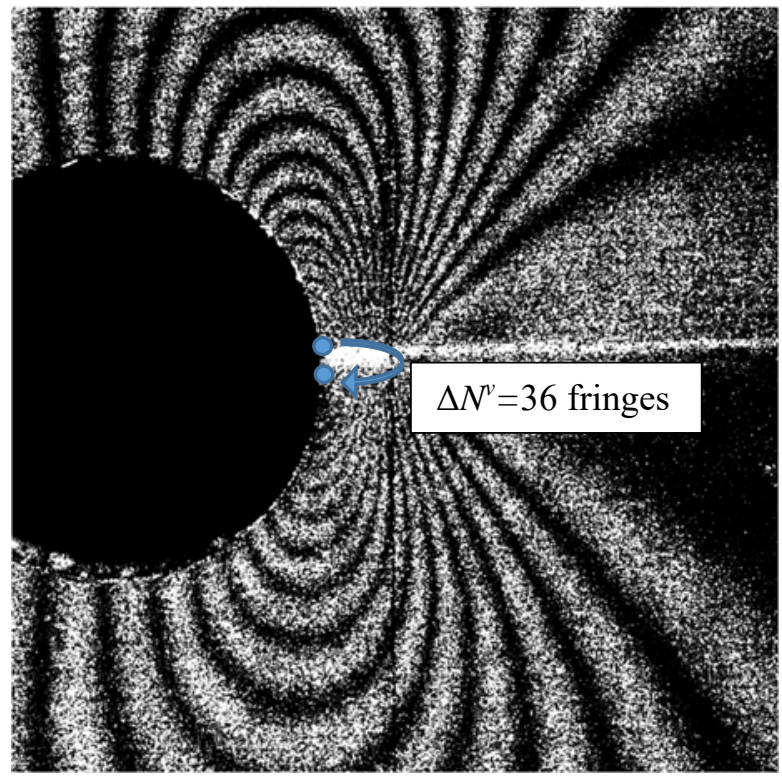

a

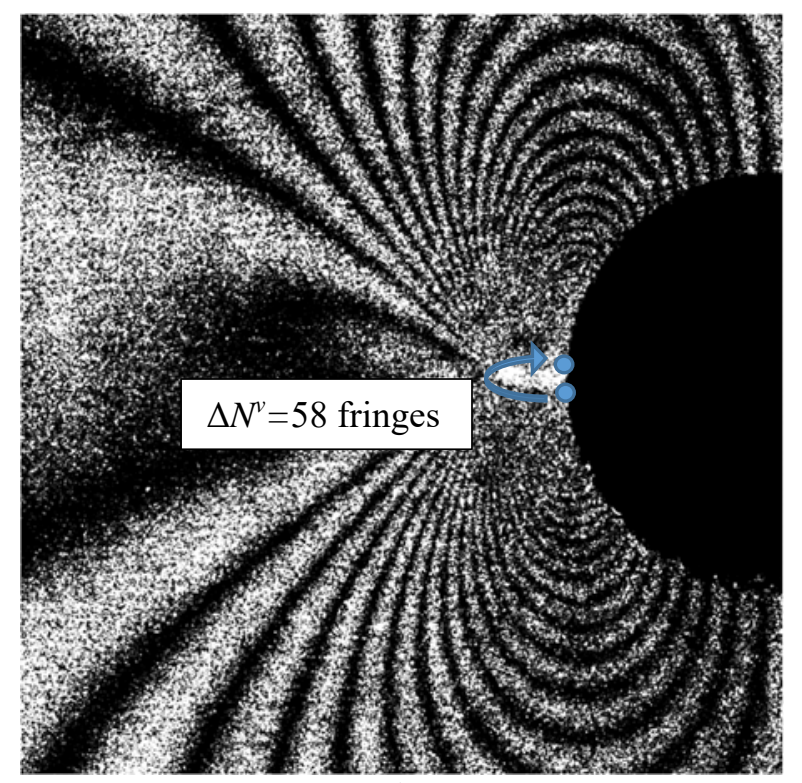

$\mathrm{b}$

Figure 2: Specimen RSH_6. Interference fringe patterns obtained in terms of in-plane displacement component $v$ on Side A (a) and Side B (b) as the result of inserting the narrow notch. Initial notch length $a_{0}=0$ with increment $\Delta a_{1}^{A}=1.81 \mathrm{~mm}$ and $\Delta a_{1}^{B}=1.74$ $\mathrm{mm}$.

Interference fringe patterns, obtained for the first notch in Specimens RSH_3 - RSH_7 in terms of displacement component $u$, are presented in Fig. 3-7. Quantifying displacement component $u$ firstly needs direct fringe counting from zero order fringe as it is shown in Fig. 3. Then required values follow from the main relation of ESPI:

$$
u=N^{u} \frac{\lambda}{2 \sin \Psi}
$$

where $u$ is in-plane displacement component in $x$-direction; $N^{u}= \pm 1 ; \pm 2 ; \pm 3, \ldots$ are the absolute fringe orders; $\lambda$ is the wavelength of laser illumination; $\Psi=\pi / 4$ is the angle between inclined illumination and normal observation directions. 


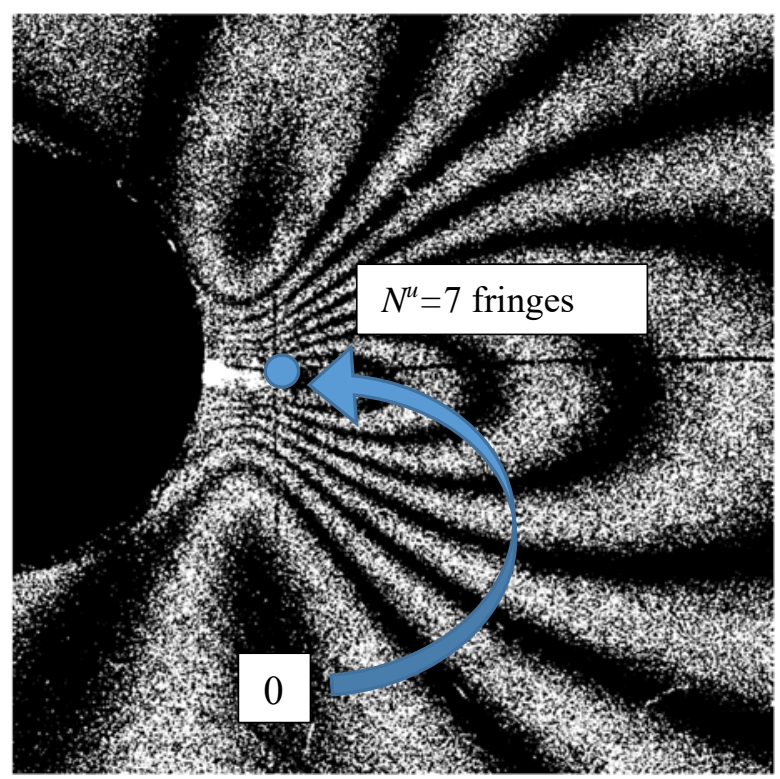

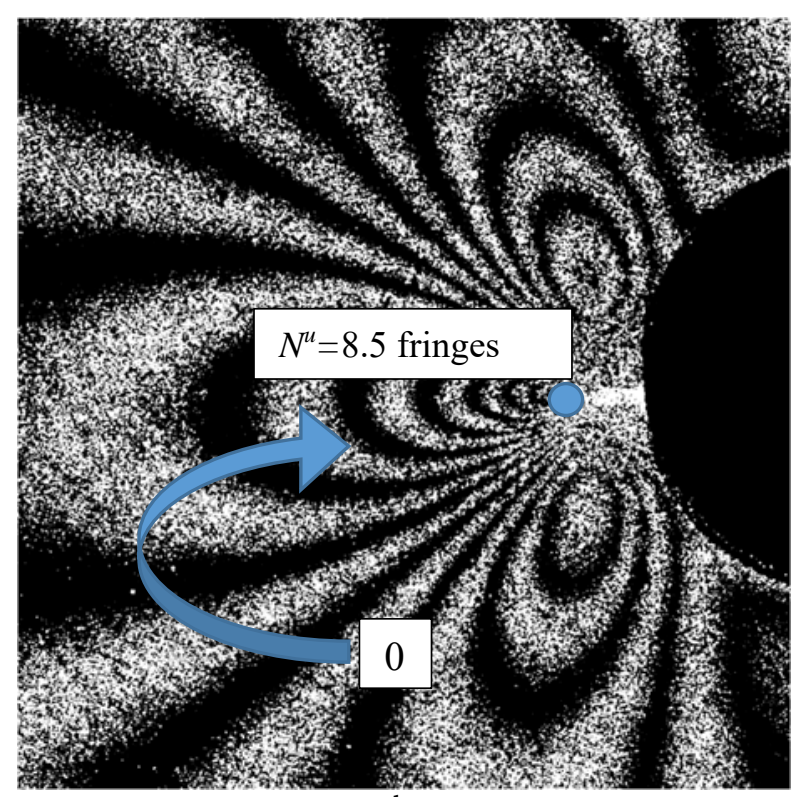

Figure 3: Specimen RSH_3. Interference fringe patterns obtained in terms of in-plane displacement component $u$ on Side A (a) and Side B (b) as the result of inserting the narrow notch. Initial notch length $a_{0}=0$ with increment $\Delta a_{1}^{A}=1.7 \mathrm{~mm}$ and $\Delta a_{1}^{B}=1.7$ $\mathrm{mm}$.

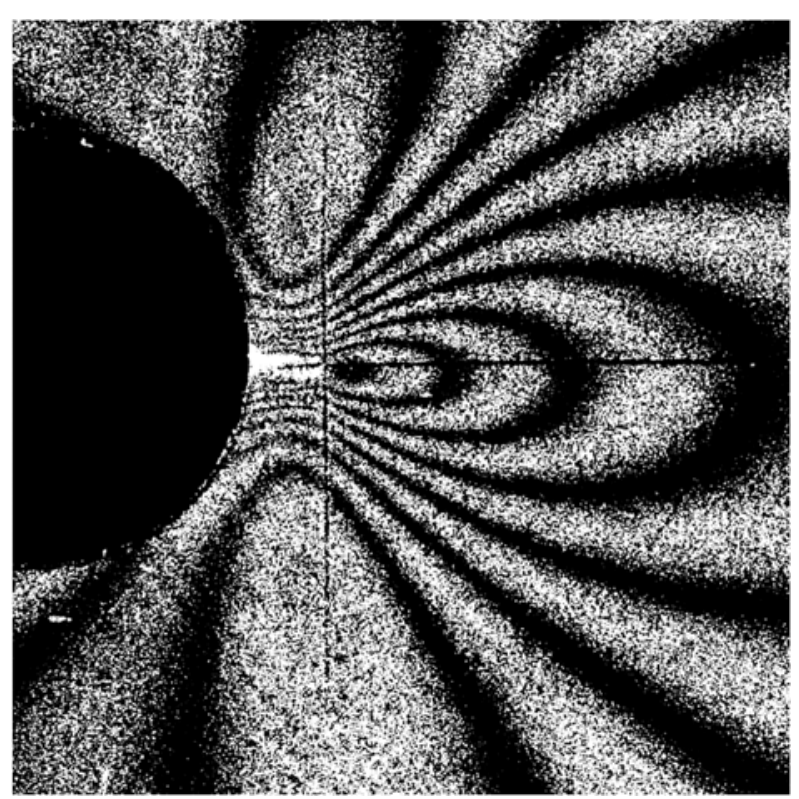

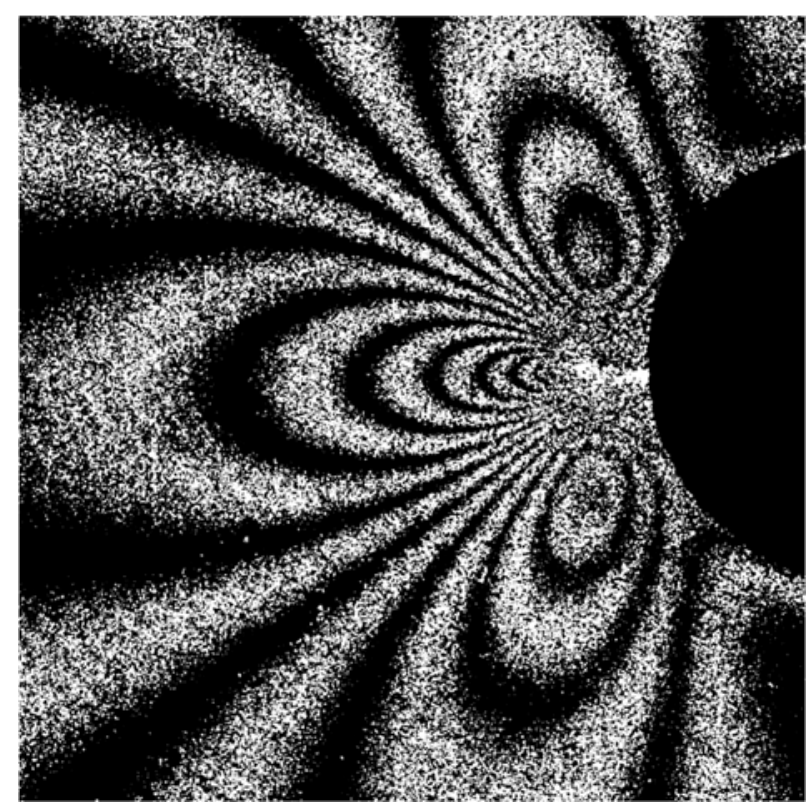

Figure 4: Specimen RSH_4. Interference fringe patterns obtained in terms of in-plane displacement component $u$ on Side A (a) and Side $\mathrm{B}$ (b) as the result of inserting the narrow notch. Initial notch length $a_{0}=0$ with increment $\Delta a_{1}^{A}=1.74 \mathrm{~mm}$ and $\Delta a_{1}^{B}=1.78$ $\mathrm{mm}$.

In-plane displacement components $u$ are served for $U_{0}$ and $U_{1}$ estimations, while $v$ displacement components are used for NMOD and SIF determination. It should be specially mentioned that the results for the first notch of $a_{1}$ length are of the main importance in respect to quantification of damage accumulation. This follows from two aspects. First, the initial notch passes through the region of elastic-plastic deformation of a high level near the hole boundary. Second, the first notch is inserted in material area, which is not impaired by previous local material removing, thus remaining a damage level caused only by high-cycle fatigue. 


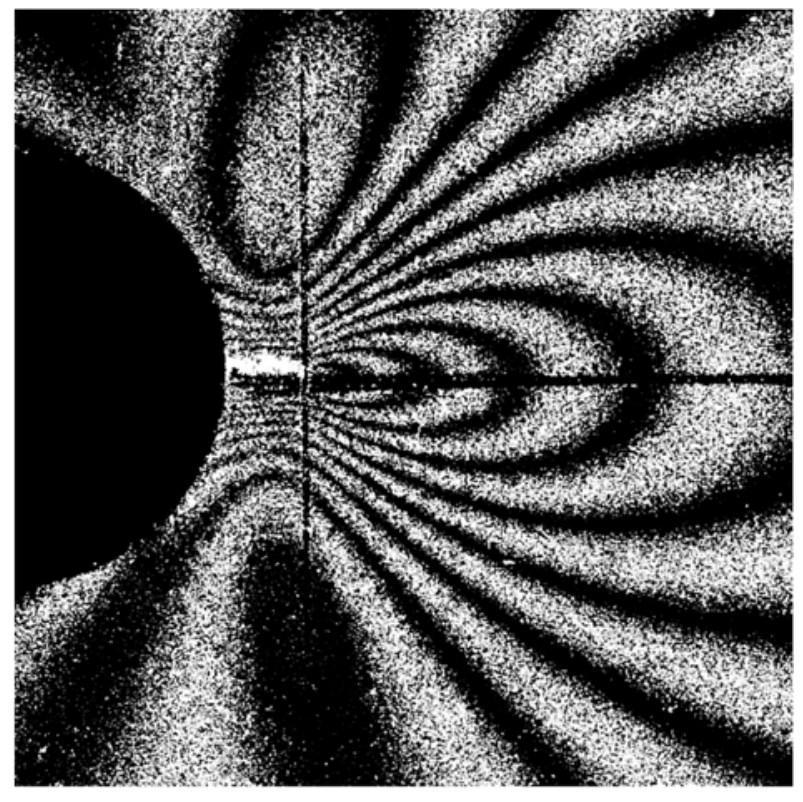

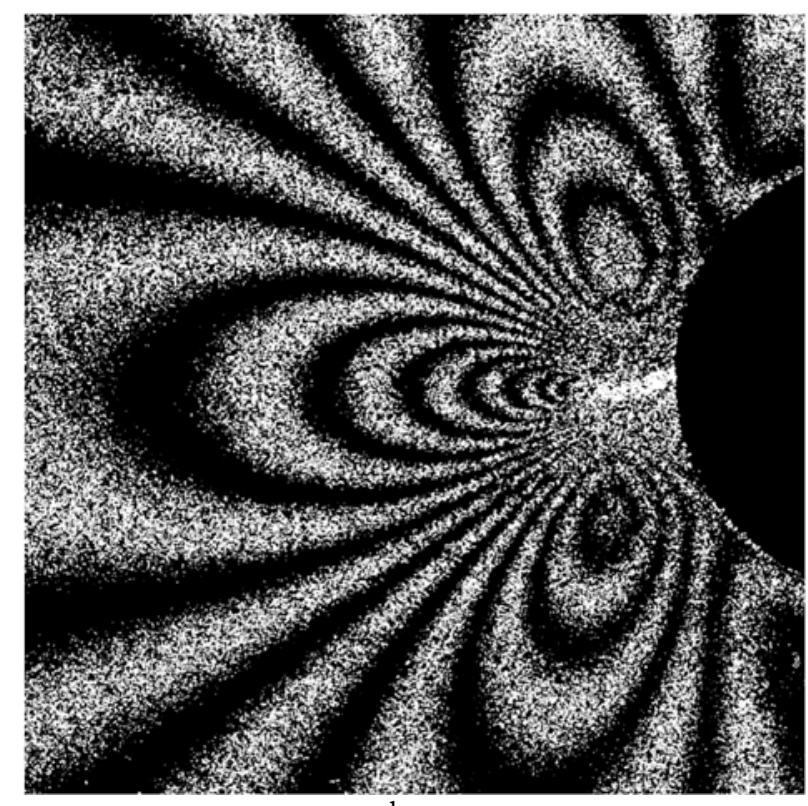

Figure 5: Specimen RSH_5. Interference fringe patterns obtained in terms of in-plane displacement component $u$ on Side A (a) and Side B (b) as the result of inserting the narrow notch. Initial notch length $a_{0}=0$ with increment $\Delta a_{1}^{A}=1.74 \mathrm{~mm}$ and $\Delta a_{1}^{B}=1.92$ $\mathrm{mm}$.

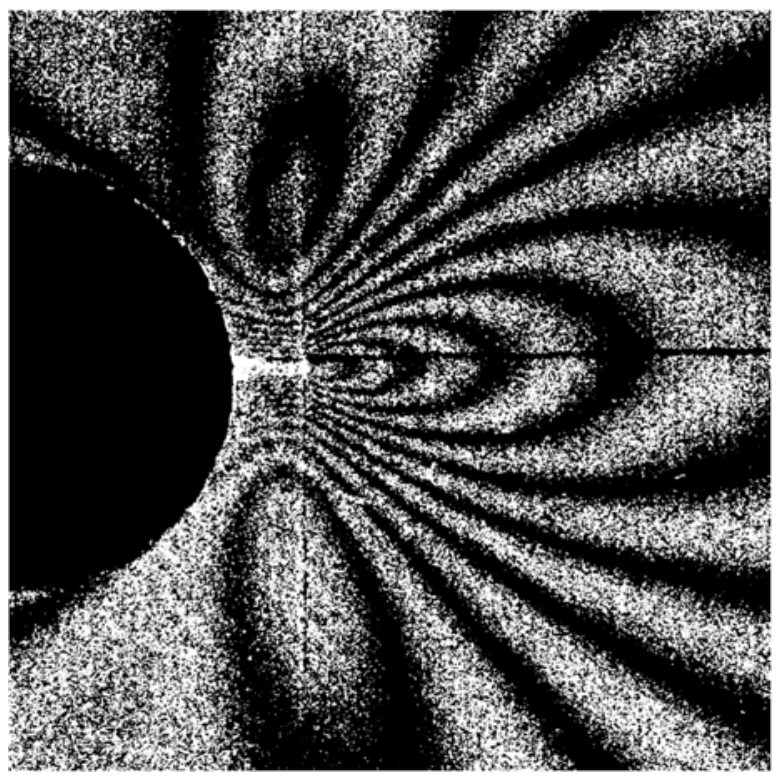

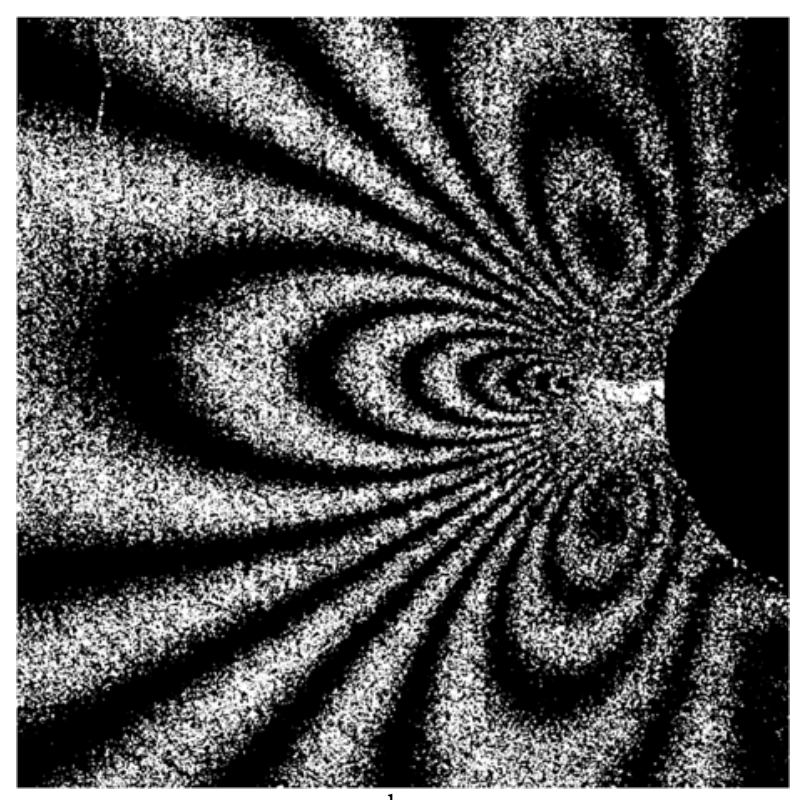

b

Figure 6: Specimen RSH_6. Interference fringe patterns obtained in terms of in-plane displacement component $u$ on Side A (a) and Side B (b) as the result of inserting the narrow notch. Initial notch length $a_{0}=0$ with increment $\Delta a_{1}^{A}=1.81 \mathrm{~mm}$ and $\Delta a_{1}^{B}=1.74$ $\mathrm{mm}$. 


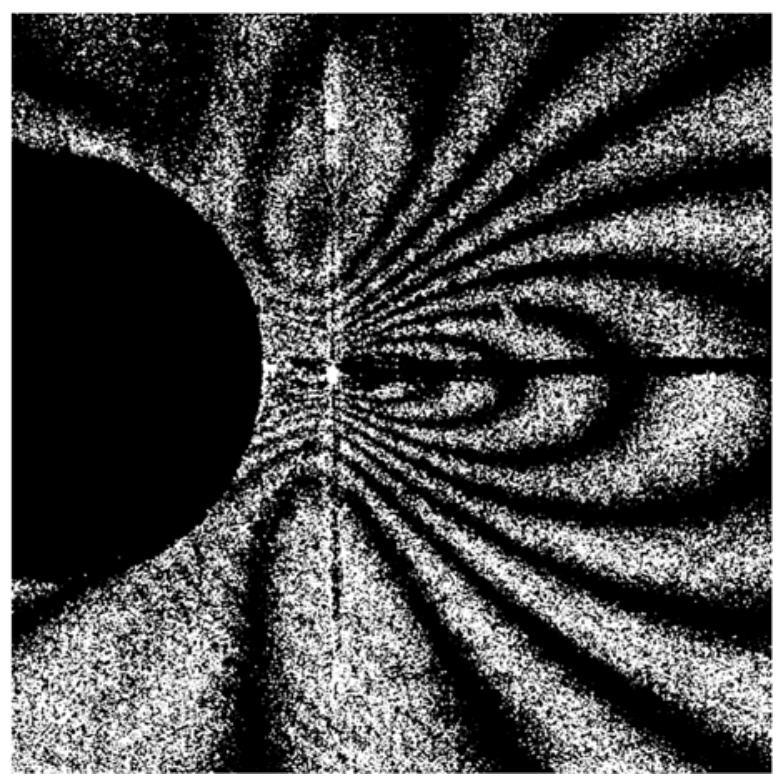

a

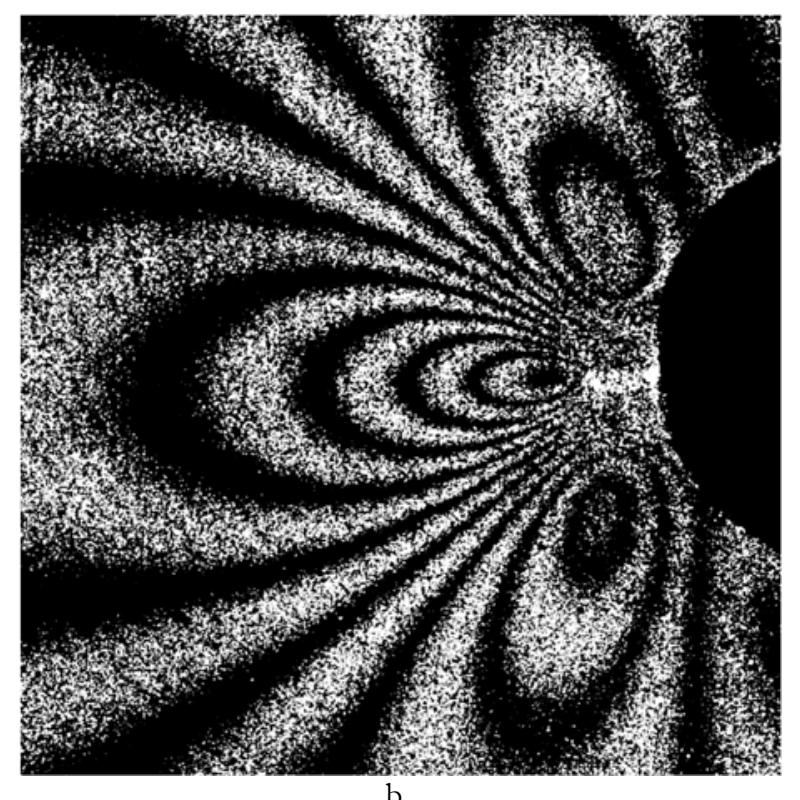

$\mathrm{b}$

Figure 7: Specimen RSH_7. Interference fringe patterns obtained in terms of in-plane displacement component $u$ on Side A (a) and Side B (b) as the result of inserting the narrow notch. Initial notch length $a_{0}=0$ with increment $\Delta a_{1}^{A}=1.81 \mathrm{~mm}$ and $\Delta a_{1}^{B}=1.81$ mm.

\section{EVOLUTION OF FRACTURE MECHANICS PARAMETERS}

$\mathrm{F}$ ull set of initial experimental data and calculated SIF values are listed in Tab. 2 and 3 for Side A and Side B, respectively.

The first column of Tab.2 and 3 includes experimentally determined values of fracture mechanics parameters, which are related to the first artificially introduced non-symmetrical notch of $a_{1}$ length: $\Delta v_{0}$ is the notch mouth opening displacement (NMOD); $u_{0}$ is in-plane displacement component acting in the notch direction and measured at the notch initial point $\left(U_{0}\right) ; u_{1}$ is in-plane displacement component acting in the notch direction and measured at the notch end point $\left(U_{1}\right) ; K_{I}^{1}$ is SIF. Experimental data presented in Tab. 2 and Tab. 3 provides fracture mechanics parameters for notches of the first length as a function of number of cycles. Distributions of these parameters, which are directly connected with fatigue damage accumulation, are presented in Fig. 8.

\begin{tabular}{cccccc}
\hline Specimen & RSH_3 & RSH_4 & RSH_5 & RSH_6 & RSH_7 \\
$a_{1}, \mathrm{~mm}$ & 1.7 & 1.74 & 1.81 & 1.81 & 1.81 \\
$\Delta v_{0}, \mu \mathrm{m}$ & -7.98 & -9.88 & -11.02 & -13.68 & -15.2 \\
$u_{0}, \mu \mathrm{m}$ & 2.09 & 1.9 & 2.28 & 2.28 & 2.09 \\
$u_{1}, \mu \mathrm{m}$ & 2.28 & 2.28 & 2.66 & 2.85 & 2.28 \\
$K_{I}^{1}, \mathrm{MPa} \times \sqrt{\mathrm{m}}$ & -4.0 & -5.6 & -4.9 & -6.9 & -9.9 \\
\hline
\end{tabular}

Table 2: The first notch length and values of fracture mechanics parameters for Side A of RSH specimens. 


\begin{tabular}{|c|c|c|c|c|c|}
\hline Specimen & RSH_3 & RSH_4 & RSH_5 & RSH_6 & RSH_7 \\
\hline$a_{1} \cdot \mathrm{mm}$ & 1.7 & 1.78 & 1.92 & 1.74 & 1.81 \\
\hline$\Delta v_{0} \cdot \mu \mathrm{m}$ & -23.18 & -20.14 & -23.18 & -22.04 & -19.0 \\
\hline$u_{0} \cdot \mu \mathrm{m}$ & 3.23 & 3.23 & 3.04 & 3.42 & 2.28 \\
\hline$u_{1} \cdot \mu \mathrm{m}$ & 3.42 & 3.42 & 3.42 & 3.8 & 2.85 \\
\hline$K_{I}^{1}, \mathrm{MPa} \times \sqrt{\mathrm{m}}$ & -11.8 & -16.7 & -21.9 & -19.7 & -11.3 \\
\hline
\end{tabular}

Table 3: The first notch length and values of fracture mechanics parameters for Side B of RSH specimens.
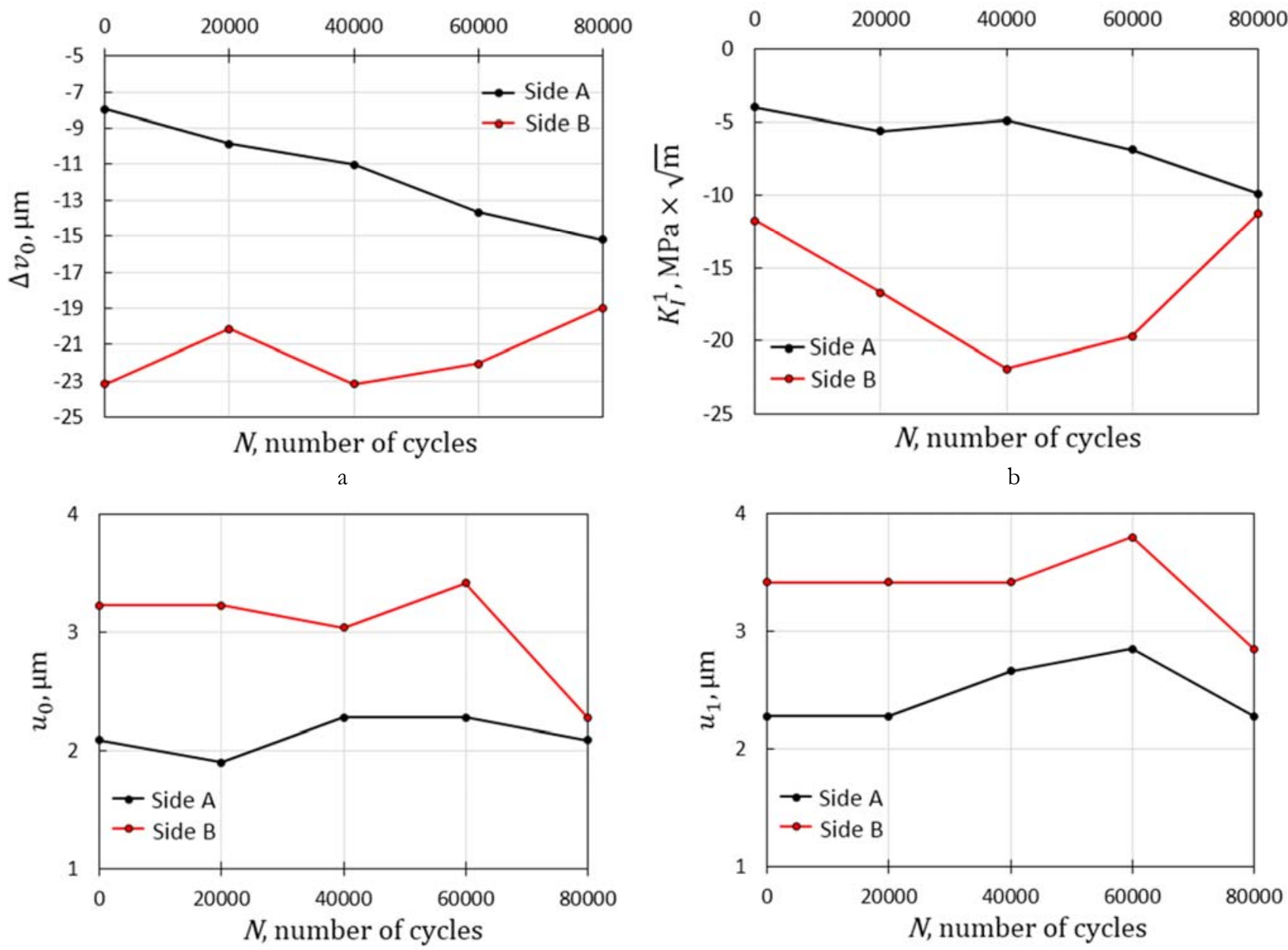

c d

Figure 8: Experimental values of fracture mechanics parameters as a function of number of cycles: for notches of $a_{1}$ length: a NMOD $\Delta v_{0} \Delta \tilde{\mathrm{v}}_{0} ; \mathrm{b}-\operatorname{SIF} K_{I}^{1} \widetilde{\mathrm{K}}_{\mathrm{I}}^{1} ; \mathrm{c}-U_{0}$, component $u_{0} ; \mathrm{d}-U_{1}$, component $u_{1}$.

Normalized evolution of NMOD, SIF, $U_{0}$ and $U_{1}$ values over lifetime, which follow from the presented results in Fig. 8, are shown in Fig. 9a, 9b, 9c and 9d, respectively. 

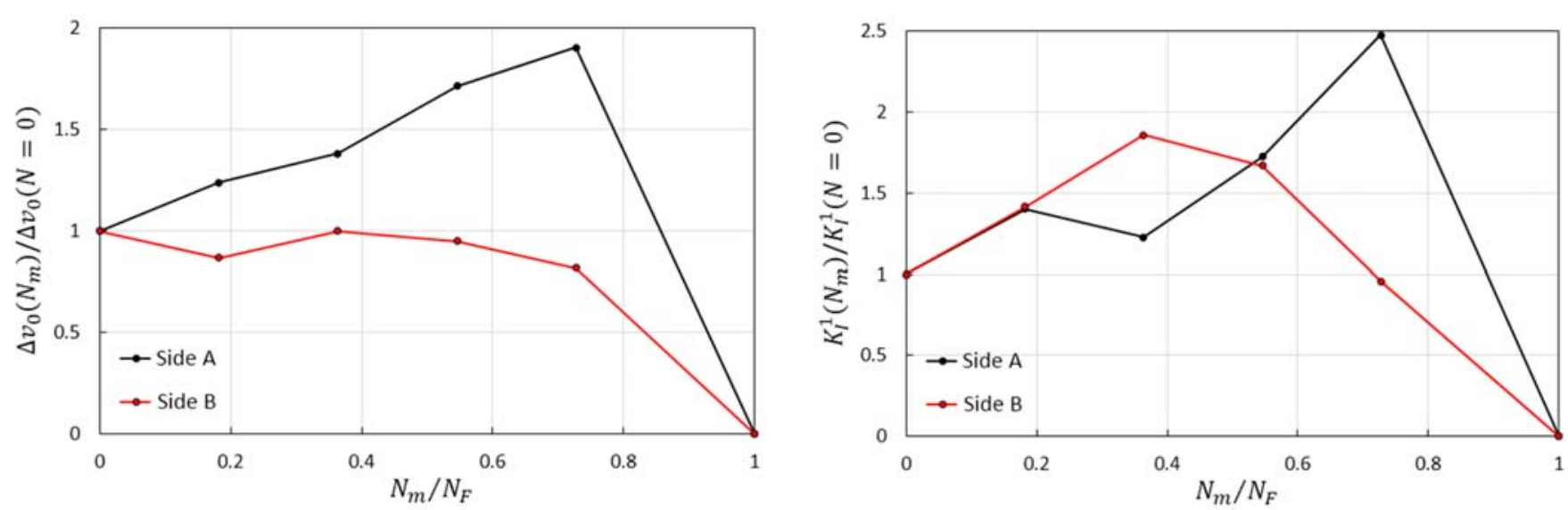

a

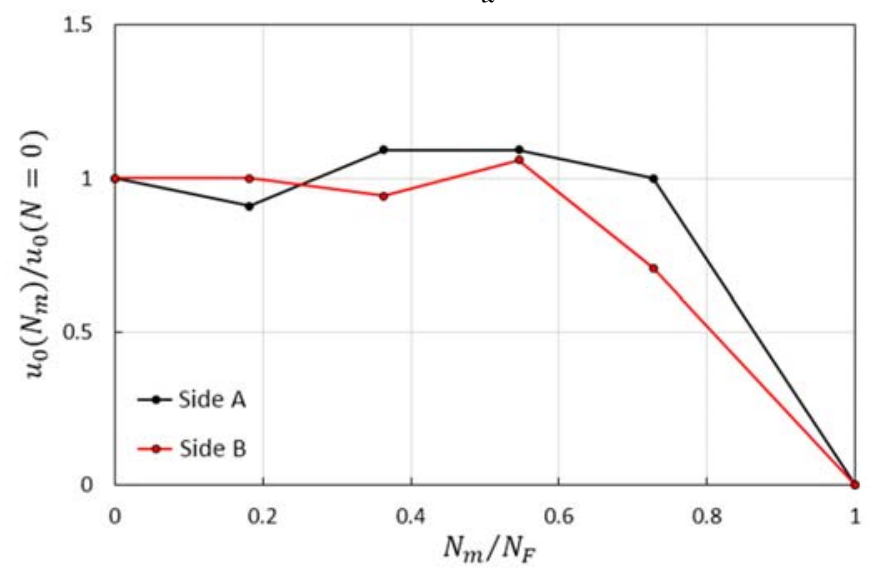

C

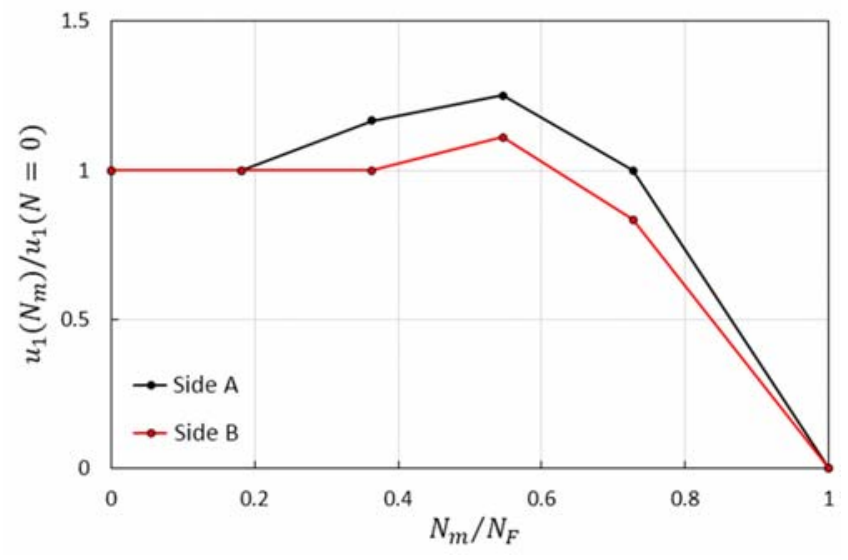

$\mathrm{d}$

Figure 9: Evolution of normalized fracture mechanics parameters for the first notch: a - NMOD $\Delta v_{0} \Delta \tilde{\mathrm{v}}_{0}$; b $-\mathrm{SIF} K_{I}^{1} \widetilde{\mathrm{K}}_{\mathrm{I}}^{1}$; c $-U_{0}$ (component $u_{0}$ ); d $-U_{1}$ (component $u_{1}$ ).

\section{THE DAMAGE ACCUMULATION FUNCTION}

he essence of the developed approach is that the evolution of each of four fracture mechanics parameters, which are referred to the artificial narrow notch inserted without applying external load, can be effectively used for quantification of damage accumulation. The performance of this methodology has been earlier demonstrated by using fracture mechanics parameters evolution, namely, NMOD, SIF and T-stress for notches emanating from throughthickness open hole in plane specimens at different stages of low-cycle fatigue [16]. This paper concerns an evolution of both non-singular (NMOD, $U_{0}, U_{1}$ ) and singular (SIF) parameters relevant to the narrow artificial notch. This approach can be implemented for quantifying damage accumulation in the vicinity of the cold-expanded hole under high-cycle fatigue conditions. It has been earlier shown that the explicit form of the damage accumulation function $D_{m}^{F M P}\left(N_{m}\right)$ can be expressed as follows [16]:

$$
D_{m}^{F M P}\left(N_{m}\right)=\sum_{N_{m}=0}^{N_{m}=N_{F}} \frac{S_{D}^{k}(F M P) \times F M P^{k}\left(N_{m}\right) \times \Delta N_{m}}{F M P^{k}\left(N_{m}=0\right) \times N_{F}},
$$

where $N_{m}$ is current number of loading cycles; $N_{m}=N_{F}$ corresponds to full failure of the specimen; FMP $P^{k}$ defines fracture mechanics parameters used for the analysis; FMP $P^{1}$ is NMOD $\Delta v_{0} ; F M P^{2}$ is $\operatorname{SIF} K_{I}^{1}$; FMP $P^{3}$ is $U_{0}$ component $u_{0} ; F M P^{4}$ is $U_{1}$ components $u_{1} ; F M P^{k}\left(N_{m}\right)$ represents a set of experimental FMP values after $N_{m}$ cycles; 
$F M P^{k}\left(N_{m}=0\right)$ is $F M P^{k}$ for the first notch length increment in the specimen without preliminary high-cycle fatigue; $N_{F}$ means number of cycles before failure; $S_{D}^{k}(F M P)$ is normalizing coefficient that must be derived from the experimental data shown in Fig. 9 for each specific FMP $P^{k}$ parameter; $\Delta N_{m}=N_{m+1}-N_{m}$ denotes number of loading cycles between two neighbouring points of $F M P^{k}\left(N_{m}\right)$ determination. It should be specially mentioned that normalized values of $F M P^{k}$, which are experimentally obtained at different stage of high-cycle fatigue, represent the key points that is essential for deriving relationship (2).

The coefficient $S_{D}^{k}(F M P)$ for specimens of given geometrical dimensions is defined by mechanical properties of the material and parameters of loading program. The value of coefficients $S_{D}^{k}(F M P)$ in each specific case follows from normalization of Eqn. (2) taking into account that the total sum in the right-hand side must be equal to one. This follows from the definition of limiting values of the damage accumulation function [16]. A square lying under each normalized $F M P^{k}$ curve (Fig. 9a, 9b, 9c and 9d) are represented by itself initial experimental information which is essential for calculation of the coefficient $S_{D}^{k}(F M P)$. This square is denoted as $\Sigma^{k}(F M P)$. Required coefficients are derived as an inverse proportional values, namely, $S_{D}^{k}(F M P)=1 / \Sigma^{k}(F M P)$. The developed procedure leads to the explicit form of the damage accumulation function (2).

\section{RESULTS AND DISCUSSION}

he essential data for a determination of the coefficient $S_{D}^{k}(F M P)$ and calculated results are presented in Tab. 4. Figs. 10a and 10b show the graphical representation of Eq. (2) for the evolution of NMOD, SIF, $U_{0} u_{0}$ and $U_{1}$ $u_{1}$ relevant to Side A and Side B, respectively.

\begin{tabular}{cccc}
\hline $\begin{array}{c}\text { Fracture } \\
\text { mechanics } \\
\text { parameter } F M P^{k}\end{array}$ & Side & $\begin{array}{c}\text { Square under normalized } \\
F M P^{k} \text { curve } \\
\Sigma^{k}(F M P) \Sigma^{\mathrm{k}}\left(\mathrm{R}_{\mathrm{i}}\right), \\
\text { Conventional Units }\end{array}$ & $\begin{array}{c}\text { Normalizing } \\
\text { coefficient } S_{D}^{k}(F M P)\end{array}$ \\
$S_{\mathrm{D}}^{\mathrm{k}}\left(\mathrm{R}_{\mathrm{i}}\right)$
\end{tabular}

Table 4: Normalizing coefficient values.

All damage accumulation curves in Fig. 10a and 10b reveal close coincidence. These dependencies quantitatively describe a difference in damage accumulation rates inherent in Side A and Side B of RSH specimens. Before more careful analyzing of above-presented plots, it should be noted that normalized distributions of fracture mechanics parameters over lifetime reveal detectable differences in configuration (Fig. 9). But, constructed damage accumulation functions look like very similar curves. Taking into account this fact, we should keep in mind that an uncertainty inherent in experimental NMOD, $U_{0}, U_{1}$ and SIF determination fit into 3, 5, 5 and 5 per cent range, respectively [17]. At the first glance all involved parameters are of equal measurement value in the course of quantifying damage accumulation. However, it must be taken into account that 5 percent accuracy of SIF determination can be reliably reached for optimal fringe density around the 
notch tip for interferograms obtained in terms of the $v$-displacement component. This density does not exceed fringe order difference $\Delta \mathrm{N}^{v}=30$ fringes between opposite notch borders at the initial point. But, interferograms provided by the $v$-displacement component on both Side A and Side B demonstrate high (Fig. 2a, $\Delta \mathrm{N}^{v}=36$ fringes) and super high fringe density (Fig. $2 \mathrm{~b}, \Delta \mathrm{N}^{v}=58$ fringes) despite of low interference level, which equals to 0.5 per cent. This is attributed to amply-dimensional value of cold-expanded hole diameter $2 r_{0}=10 \mathrm{~mm}$. In the case under consideration, the uncertainty inherent in determining the stress intensity factor is about $10 \%$. Thus, non-singular fracture mechanics parameters, namely, NMOD, $U_{0}$ and $U_{1}$ are favoured as current damage indicators compared to the singular SIF.

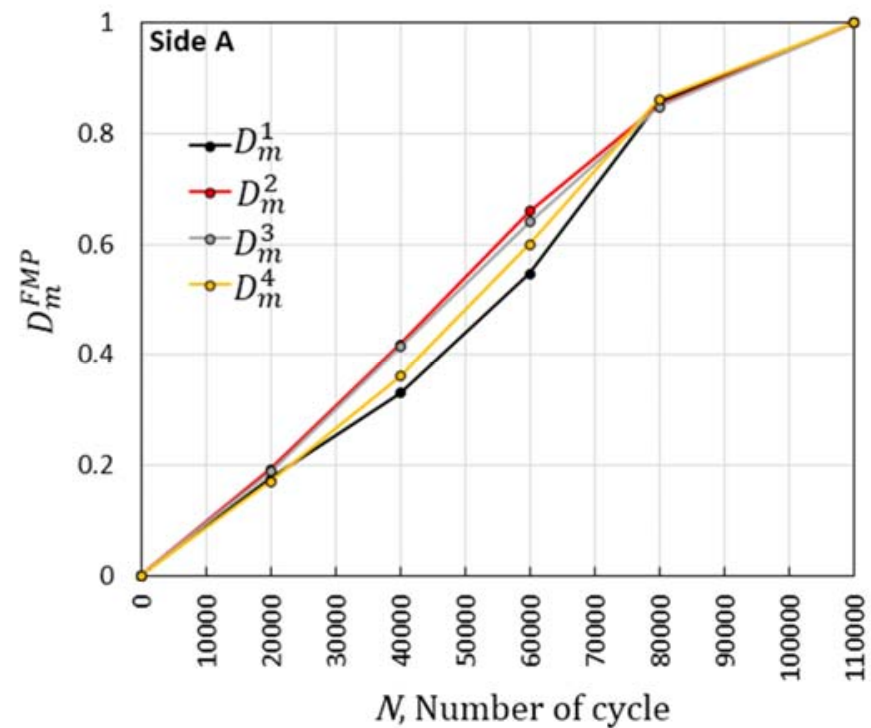

a

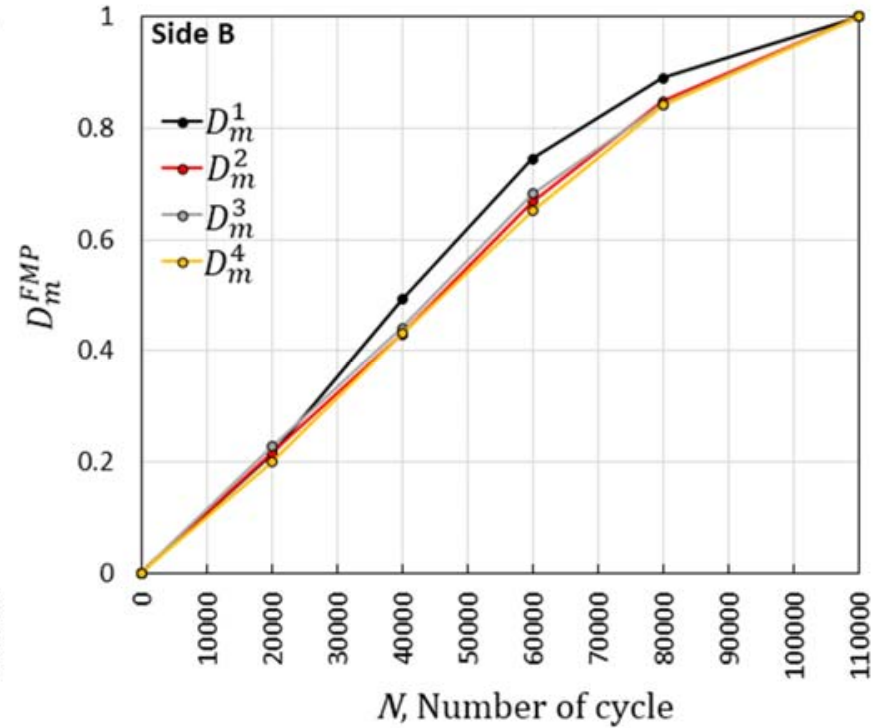

$\mathrm{b}$

Figure 10: The damage accumulation functions $D_{m}^{F M P}\left(N_{m}\right)$ constructed by using different fracture mechanics parameters related to Side A (a) and Side B (b) of RSH specimens.

The following question is: «Which from non-singular indicators is the most preferable and reliable with respect to the measurement procedure»? The comparative analysis of interference fringe patterns shown in Figs. $2-7$ clearly evidences that the parameter $U_{1}$ is best suited to quantitative interpretation. Naturally, values of the in-plane displacement component $u_{1}$ at the end notch point acting in the notch direction can be reliably extracted from all interferograms by direct counting fringes, as it is shown in Fig. 3. Damage accumulation functions, generated by all three non-singular parameters, are practically coincided. This is especially true for Side B data. Thus, it is established that involving $U_{1}$ evolution looks like the most simple and reliable way to quantify damage accumulation due to high-cycle fatigue near the cold-expanded hole.

The first advantage of using $U_{1}$ as the current damage indicator consists of straightforward and accurate character of the measurement procedure. In-plane displacement components $u_{1}$ directly follow from interpretation of interference fringe patterns generated by ESPI. The second benefit resides in the absence of need to apply external tensile stress during inserting the notch and further measurements of in-plane displacement components. It has been previously shown that the level of residual stress corresponding to 4-6\% expansion degree is so high that inserting the narrow notch without external tensile load leads to interference fringe pattern of super-high fringe density [18-19]. These fringes cannot be resolved to derive in-plane displacement components. Thus, tensile external stress plays a role of anti-amplifier to reduce initially redundant signal. This fact immediately adds complexity to the interferometer optical system that must include low-size testing machine as essential component. Moreover, such approach makes two-side measurements impossible. The approach based on involving $U_{1}$ as the current indicator of damage opens a way to two-side measurements of significant values of the level of cold expansion. To support this statement, let us consider a plane specimen (RSH_X) of dimensions $180 \times 30 \times 5 \mathrm{~mm}$, which is made from AA2024A-T3 aluminium alloy, with a centred cold-expanded throughthickness hole of nominal diameter $2 r_{0}=4.0 \mathrm{~mm}$. The expansion level is $5 \%$ of nominal interference. The symmetrical 
narrow notch is inserted before fatigue loading without applying external stress. The obtained interferograms are shown in Fig. 11 and Fig. 12 for in-plane displacement components $u$ and $v$, respectively.

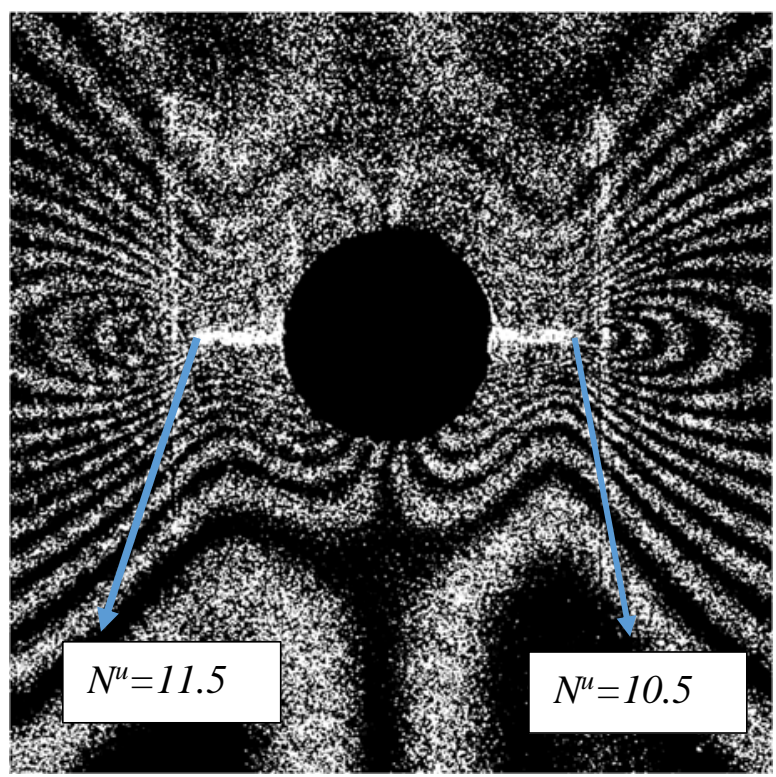

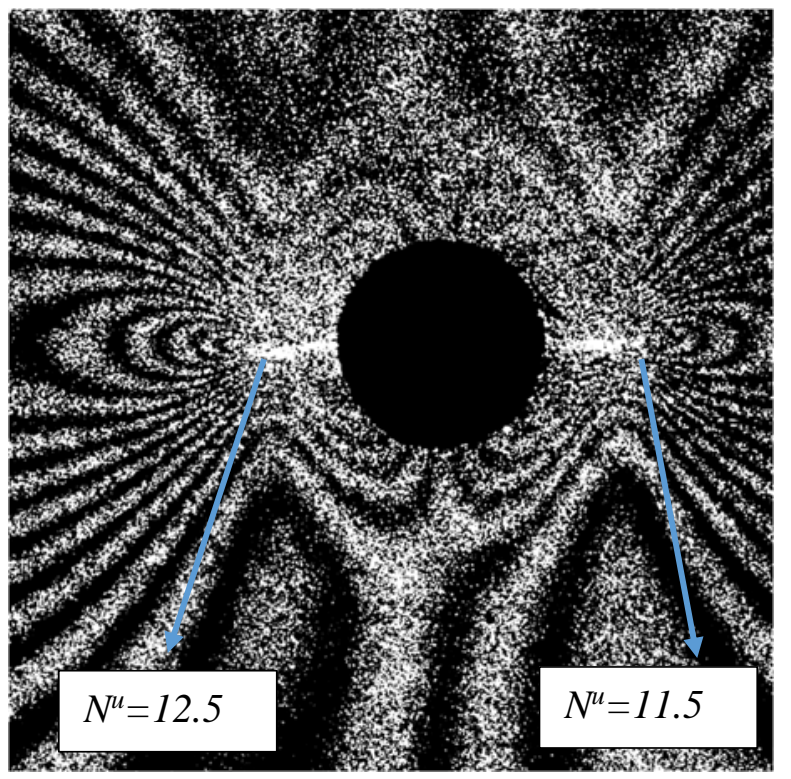

Figure 11: Specimen RSH_X. Interference fringe patterns obtained in terms of the in-plane displacement component $u$ in Side A (a) and Side B (b) as a result of inserting the narrow notch. Initial notch length $a_{0}=0$ with increment $\Delta a_{1}^{A}=2.24 \mathrm{~mm}$ and $\Delta a_{1}^{B}=2.08$ mm.

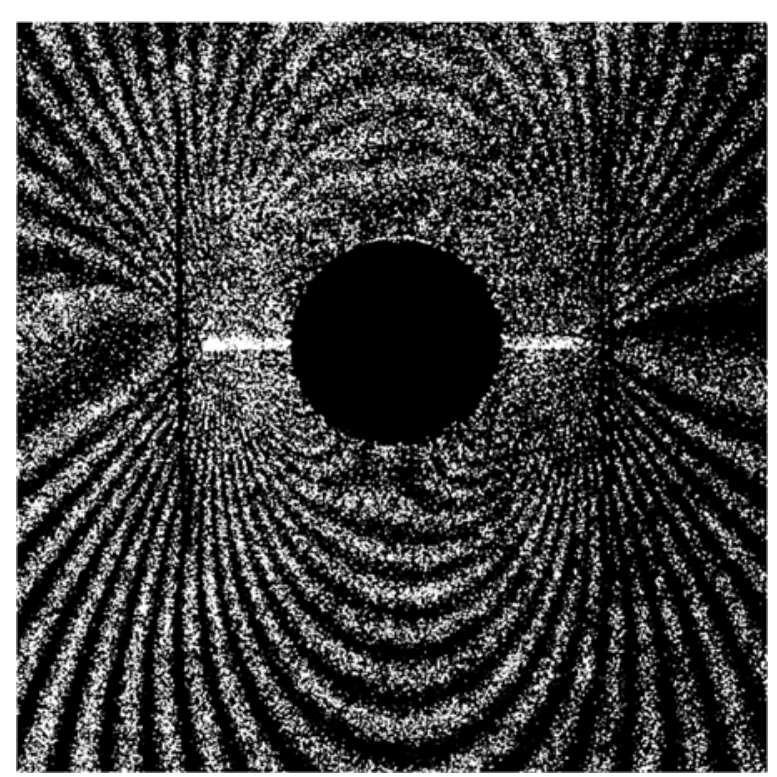

a

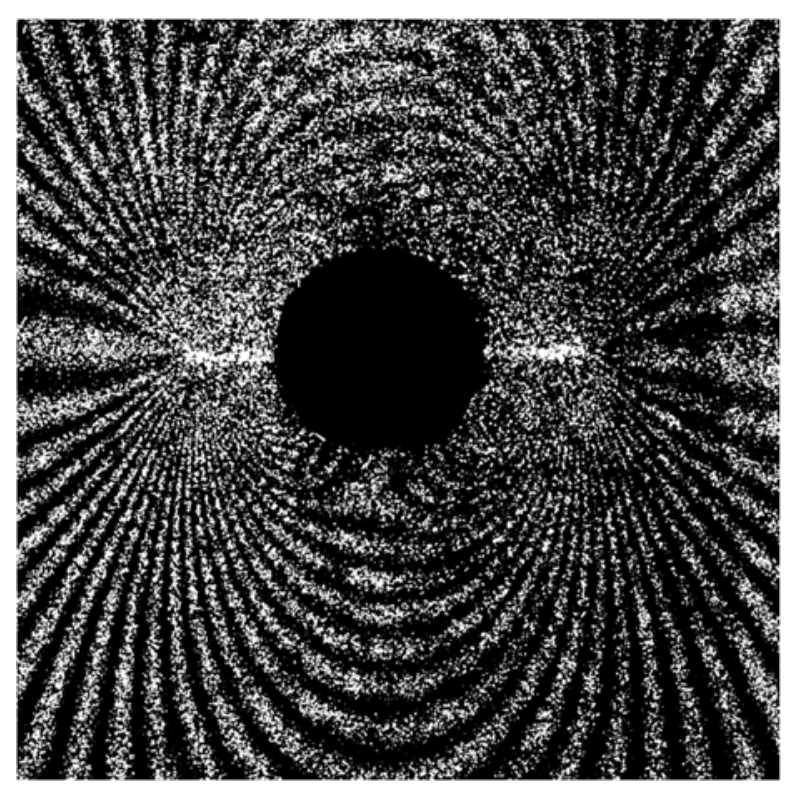

$\mathrm{b}$

Figure 12: Specimen RSH_X. Interference fringe patterns obtained in terms of the in-plane displacement component $v$ in Side A (a) and Side B (b) as a result of inserting the narrow notch. Initial notch length $a_{0}=0$ with increment $\Delta a_{1}^{A}=2.24 \mathrm{~mm}$ and $\Delta a_{1}^{B}=2.08$ $\mathrm{mm}$.

Presented interferograms clearly evidence that only the $U_{1}$-parameter can be reliably extracted from interference fringe patterns shown in Fig. 11a and 11b. There is no way to derive NMOD, $U_{0}$ and SIF values. Another approach aimed at quantifying two-side damage accumulation employs the secondary hole drilling technique [22]. The secondary hole diameter increments in principal strain directions can be also used as current damage indicators. However, it should be 
noted that careful drilling of the secondary hole is more complex technical procedure compared with inserting the narrow notch.

\section{CONCLUSIONS}

7 he novel destructive method is used for quantitative assessment of fatigue damage accumulation caused by highcycle fatigue and residual stresses in the vicinity of the cold-expanded hole. The developed approach employs preliminary high-cycle fatigue loading of specimens with cold-expanded holes up to prescribed number of cycles and subsequent inserting the narrow notches without applying external load. The last fact provides a way for the analysis of damage accumulation on opposite sides of the specimen. The fracture mechanics parameters of artificially created notches have been attracted as indicators of current damage to quantify damage accumulation in the vicinity of holes. A measurement of deformation response, caused by local material removing in terms of in-plane displacement components, is performed by ESPI. The transition to the required SIF follows from the relationships developed within of the modified version of the crack compliance method. Inserted notches serve to manifest the level of fatigue damage accumulation as well as a probe hole is used for residual stress energy release in the hole-drilling method. It has been established that normalized NMOD, $U_{0}, U_{1}$ and SIF values, which are obtained for the narrow notch emanating from the cold-expanded hole at different stages of high-cycle fatigue, can be reliably involved into the analysis as representative damage indicators. Numerical integration of evolution curves produces the damage accumulation function. The required coefficient is derived as an inverse proportional value with respect to a square lying under normalized distribution of specific fracture mechanics parameter over lifetime. The proposed procedure defines an explicit form of the damage accumulation function. These functions are constructed by using the evolution of NMOD, $U_{0}, U_{1}$ and SIF. It is shown that the lifetime evolution of non-singular (NMOD, $U_{0}, U_{1}$ ) and singular (SIF $\beta$ ) fracture mechanics parameters lead to very close damage accumulation functions. Obtained data shows that fatigue damage accumulation can be characterized on a base of direct measurements of any from two in-plane displacement components relevant to starting point of inserted narrow notches. The main result resides in the fact that an evolution of the in-plane displacement component at the end notch point acting in the notch direction $\left(U_{1}\right)$ represents the most simple and reliable way to quantify damage accumulation due to high-cycle fatigue near the cold-expanded hole. The developed approach gives rise remarkable capability of revealing a difference in damage accumulation rates inherent in opposite specimen's sides with different level of residual stresses.

\section{ACKNOWLEDGEMENTS}

he authors acknowledge the support of the Russian Science Foundation (project N 18-19-00351).

\section{REFERENCES}

[1] Reid, L. (2014). Hole Cold Expansion - The Fatigue Mitigation Game Changer of the Past 50 Years, Advanced Materials Research, 891-892, pp. 679-684. DOI: 10.4028/www.scientific.net/AMR.891-892.679.

[2] Stefanescu, D. (2004). Measurement and prediction of fatigue crack growth from cold expanded holes, part 1: the effect of fatigue crack growth on cold expansion residual stresses, J. of Str. Analysis, 39(1), pp. 25-39. DOI: $10.1177 / 030932470403900103$.

[3] Zuccarello, B., Di Franco, G. (2013). Numerical-experimental Method for the Analysis of Residual Stresses in Coldexpanded Holes, Exp. Mechanics; 53(4), pp. 673-686. DOI:10.1007/s11340-012-9669-2.

[4] Ozdemir, A. T., Edwards, L. (1997). Relaxation of residual stresses at cold worked fastener holes due to fatigue loading, Fatigue Fract. Eng. Mater. Struct. 20(10), pp. 1443-1451. DOI:10.1111/j.1460-2695.1997.tb01501.x.

[5] Chakherlou T. N., Yaghoobi, A. (2010). Numerical simulation of residual stress relaxation around a cold-expanded fastener hole under longitudinal cyclic loading using different kinematic hardening models, Fatigue \& Fracture of Engineering Materials \& Structures, 33(11), pp. 740-751. DOI: 10.1111/j.1460-2695.2010.01485.x.

[6] Backman, D., Cowal, C., Patterson, E.A. (2010). Analysis of the effects of cold expansion of holes using thermoelasticity and image correlation, Fat. \& Fract. of Eng. Mat. \& Struct., 33(12), pp. 859-870. 
DOI:10.1111/j.1460-2695.2010.01472.x.

[7] Boni, L., Fanteria, D., Lanciotti, A., Polese, C. (2013). Experimental and analytical assessment of fatigue and crack propagation in cold worked open hole specimens, Fatigue Fract. Engng. Mater Struct., 36(9), pp. 930-941. DOI: $10.1111 /$ ffe.12050.

[8] Fu Y., Ge E., Su H., Xu J., \& Li R. (2015). Cold expansion technology of connection holes in aircraft structures: A review and prospect. Chinese Journal of Aeronautics, 28(4), pp. 961-973.

[9] Keith, W.J., Ralph, W.B. (2017). Investigation of residual stress relaxation in cold expanded holes by the slitting method, Eng. Fract. Mech., 179, pp. 213-224. DOI: 10.1016/j.engfracmech.2017.05.004.

[10] Wang Y., Zhu Y., Hou S., Sun H., \& Zhou Y. (2017). Investigation on fatigue performance of cold expansion holes of 6061-T6 aluminum alloy, International Journal of Fatigue, 95, pp. 216-228. DOI: 10.1016/j.ijfatigue.2016.10.030.

[11] Mohamed El Habiri, Mustapha Benachour, Nadjia Benachour. (2018). Effect of cold expansion on improving of fatigue initiation life in Aluminium alloy, Frattura ed Integrità Strutturale, 46, pp. 34-44.

DOI: 10.3221/IGF-ESIS.46.04.

[12] Eleonsky, S.I., Pisarev, V.S., Zajtsev, D.M., Zinchenkov, M.Ch., Abullin, M.R. (2021). Residual stresses near coldexpanded hole at different stages of high-cycle fatigue by crack compliance data, Frattura ed Integrità Strutturale, 56, pp. 171-186. DOI: 10.3221/IGF-ESIS.56.14.

[13] Garcia, S., Amrouche, A., Mesmacque, G., Decoopman, X., Rubio, C. (2005). Fatigue damage accumulation of cold expanded hole in aluminum alloys subjected to block loading. International Journal of Fatigue, 27(10), pp. 1347-1353.

[14] Mostefa, B., Abdelkrim, A., Ali, B., Mohamed, B. (2012). Effect of hardening induced by cold expansion on damage fatigue accumulation and life assessment of aluminum alloy 6082 T6, Materials Research, 15(6), pp. 981-985.

DOI: $10.1590 /$ S1516-14392012005000123.

[15] Ying Sun, Weiping Hu, Fei Shen, Qingchun Meng, Yuanming Xu. (2016). Numerical simulations of the fatigue damage evolution at a fastener hole treated by cold expansion or with interference fit pin, International Journal of Mechanical Sciences, 107, pp. 188-200. DOI: 10.1016/j.ijmecsci.2016.01.015.

[16] Matvienko, Yu.G., Pisarev, V.S., Eleonsky, S.I. (2021). Evolution of fracture mechanics parameters relevant to narrow notch increment as a measure of fatigue damage accumulation. International Journal of Fatigue, 149, 106310. DOI: 10.1016/j.ijfatigue.2021.106310.

[17] Pisarev, V.S., Matvienko, Y.G., Eleonsky, S.I., Odintsev, I.N. (2017). Combining the crack compliance method and speckle interferometry data for determination of stress intensity factors and T-stresses, Eng. Fract. Mech., 179, pp. 348-374. DOI: 10.1016/j.engfracmech.2017.04.029.

[18] Matvienko, Y.G., Pisarev, V.S., Eleonsky, S.I. (2019). The effect of low-cycle fatigue on evolution of fracture mechanics parameters in residual stress field caused by cold hole expansion, Fratt. ed Int. Str., 13(47), pp. 303-320. DOI: $10.3221 /$ IGF-ESIS.47.23.

[19] Chernov, A.V., Eleonsky, S.I., Pisarev, V.S. (2021). Influence of stress ratio on residual stress evolution near coldexpanded hole due to low-cycle fatigue by crack compliance data, Fratt. ed Int. Str., 55, pp. 174-186; DOI: 10.3221/IGF-ESIS.55.13.

[20] Moreira, P.M.G.P., De Matos, P.F.P., Pinho, S.T., Pastrama, S.D., Camanho, P.P., De Castro, P.M.S.T. (2004). The Residual Stress Intensity Factors for Cold-Worked Cracked Holes: a Technical Note, Fatig. \& Fract. of Eng. Mat. \& Struct., (27), pp. 879-886. DOI:10.1111/j.1460-2695.2004.00768.x.

[21] Pisarev, V.S., Odintsev, I.N., Eleonsky, S.I., Apalkov, A.A. (2018). Residual stress determination by optical interferometric measurements of hole diameter increments, Optics and Lasers in Engineering, 110, pp. 437-456, DOI: 10.1016/j.optlaseng.2018.06.022.

[22] Matvienko, Y.G., Pisarev, V.S., Eleonsky, S.I. (2019). Residual stress/strain evolution due to low-cycle fatigue by removing local material volume and optical interferometric data, Fat. \& Fract. of Eng. Mat. \& Struct., 42, pp. 20612078. DOI:10.1111/ffe.13083. 